\title{
Are we training optimistic physicians? A cross sectional survey to measure correlates of optimism among Pakistani medical students
}

Umar Farooq Dar

Departments of Family \& Community Medicine,College of Medicine, Jouf University,

Sakaka, Saudi Arabia

For correspondence:ufdar@ju.edu.sa

Mobile Number: +966 582461655

\begin{abstract}
Background :

Optimism and pessimism affect physicians' behavior and play important roles in shaping the future characteristics of a medical student. We carried out the study to measure optimism and pessimism scores among medical students and its association with important correlates i.e. duration of study in medical college, gender and intended future specialty.

Participants and Method: A cross-sectional study was conducted in Gujranwala Medical College, Pakistan. Using non-probability consecutive sampling, the data was anonymously collected from consenting 150 students from all classes (1st, 2nd, 3rd, 4th \& final year). Optimism/pessimism score was measured using Life Orientation Test - Revised (LOT-R). LOT-R is a valid tool containing ten items to be rated on a scale from zero to four (strongly agree to strongly disagree). Threeitems are related to optimism, three with pessimism and four are fillers only. Score in one domain can range from zero to twelve. Higher score indicates higher value. We measured association of optimism/pessimism scores with gender, specialty preference, class year and living status.

Results: The mean $( \pm \mathrm{SD})$ optimism and pessimism scores were 8.16 \pm 2.4 and $5.35 \pm 1.95$ respectively while median scores (Q1-Q3) were 9 (7-10) and 5 (4-7). Mean age of study population was $21.6 \pm 1.7$ years. Majority of the responders ( $\mathrm{n}, \%)$ were females $(116,77.3 \%)$, from fourth year class $(45,30 \%)$ and living alone away from family $(107,71.3 \%)$. Among 150 responders, 99 students $(66 \%)$ were planning to opt a people oriented specialty in future. Optimism score was significantly lower among male compared to female students $(p=0.019)$. Pessimism scores were higher among students living with their family $(p=0.008)$. Specialty preference and year of study has shown no effect on either score. $(p>0.05)$

Conclusion: The result showed that our medical students are optimistic. Pessimism was affected by current living status. Female students were found more optimistic compared to their male counterparts.

Key words:Empathy, Medical education, Optimism, Pessimism, Life orientation, Burnout, Coping
\end{abstract}

\section{Introduction}

Optimism is defined as "a positive human trait that enables humans to look on more favorable sides of the events and to expect the best irrespective of the situation". 1, 2 Optimism is a powerful cognitive filter that plays an important role in influencing individual views of events and their adaptations and reactions to events. ${ }^{3}$ Optimism was found to be an important valid augur of a sense of meaningful life. Scarce data are available regarding optimism and pessimism among medical students i.e. future physicians. ${ }^{4}$ Optimistic attitude among the treating physicians lead to inculcation of hope and improvement in treatment adherence. A pessimistic approach leads to despair. ${ }^{5-7} \mathrm{In}$ previous studies, the optimistic patients even with 
grave and severe diseases like cancer and heart failure have shown a better quality of life measurement and courage to challenging situations. 8,9

Pessimistic patients have poor adherence to treatment and poor quality of life in difficult situations. Existing literature propose a medical student to be optimistic and enthusiastic. ${ }^{1,} 10$ Optimistic students also perform well in academics and find a positive way out in all situations. They are less likely to be burnt out and depressed. 6, 11, 12 In a research based on emotional intelligence among medical students in Pakistan, they said that empathy and optimism are important tools for feelings of others, communal obligations and interpersonal interaction but traditional system of medical education may be unable to inculcate these characteristics. ${ }^{13}$

Despite the importance of optimism in medical field, there is limited empirical research in context of medical education and patient care among Pakistani medical graduates. The available data are for the students living in European and developed countries. There is no local study available regarding the measurement of optimism and pessimism among Pakistani medical students, who have different social brought up and principles of faith. Therefore, we expect different results compared to the developed countries. We tested four hypothesis that optimism/pessimism scores are associated with gender, year of study, living status and future specialty preference of medical students.

\section{Participants and Methods}

We carried out a cross-sectional studywith an analytic component in Gujranwala Medical College, Gujranwala, Punjab, Pakistan from June 2015 to January 2016. Average strength of undergraduates in this public sector medical college is about 500 students; approximately 100 students in each class with 3:1 female to male ratio. Required sample size was 142 (rounded off to 150) at 95\% confidence level and $7 \%$ margin of error expecting
$50 \%$ of students to be optimistic. Winpepi(PEPIfor-Windows)was used to calculate sample size. We utilized non-probability consecutive sampling to recruit the students from all five classes. Participation was voluntary after verbal informed consenting. The study was approved from local ethical review board of Gujranwala Medical College, Gujranwala.

A self-administered proforma was used which contained demographic data and the Life orientation Test-Revised (LOT-R) was used for measuring optimism along with the un-identifying sociodemographic characteristics of respondents. LOT$R$ is a valid and reliable test used for measuring optimism among general population. 1, 2, 10, 14, 15 The test consisted of 10 -items, which were rated on a 5-point Likert scale ranging from strongly disagree to strongly agree. Three items measure optimism, three items measure pessimism while four items are filler only. The weightage to each response form the respondents is as follows: $0=$ Strongly disagree, 1= Disagree, 2=Neutral, $3=$ Agree and $4=$ Strongly agree. $16-18$ Optimism and pessimism scores were separately calculated as the two can coexist as a result of psychological defense mechanisms. ${ }^{1,} 10$

Respondents were asked to fill in their gender, year of study, current living status (with family or in hostel) and future specialty preferences. Regarding specialty preferences, we asked "what is the specialty that you might consider choosing in the future?" Eight possible specialty choices were listed that were broadly classified as peopleoriented (primary care, gynecology lobstetrics, psychiatry, pediatrics, and internal medicine) and technology-oriented (general \& laparoscopic surgery, orthopedics, radiology, and anesthesiology).We distributed 175 questionnaires consecutively among students of five classes and received 150 completely filled questionnaires (response rate about $86 \%$ ).

Data were collected and analyzed using SPSS version 23.0 (Statistical package for social scienc- 
es). Data were described using frequencies and percentages for qualitative variables like gender, and living status, and, as mean \pm SD for quantitative variables like optimism and pessimism scores. Shapirowilk test was applied to measure the normality of scores. Independent sample $t$ test was applied to determine the distribution of mean scores in binary categories of gender, living status and specialty preference if data was normally distributed otherwise independent median samples test or Mann Whitney $U$ test was applied. The distribution of optimism and pessimism scores in the study population was not normal i.e. when we applied Shapirowilk test the results were statistically significant. We have to use nonparametric statistical tests due to non-normal distribution of the scores. We applied Kruskal Wallis test to determine the score distribution across the five years because assumption for ANOVA were not met. Box plots were used for graphical presentation of the data. $P$ value $<0.05$ was considered as significant.

\section{Results :}

Mean age of the participantsin this study was 21.6 \pm 1.7 years. There were 34 male $(22 \%)$ and 116 female $(78 \%)$ students. The response rate was
$85.7 \%$. The study participants included $1^{\text {st }}$ year $(11.3 \%)$ 2nd year $(20.7 \%)$ 3rd year (18\%) 4th year $(30 \%)$ final year $(20 \%)$ medical students out of which day scholar and hostellites were $28.7 \%$ and $71.3 \%$ respectively. 75 students $(50 \%)$ were in their clinical years. $34 \%$ students intended to join technology oriented specialties in future. Table 1 presents sociodemographic data of included participants. In this study participants, mean $( \pm S D)$ optimism and pessimism scores were $8.16 \pm 2.4$ and $5.35 \pm 1.95$ while median scores (Q1-Q3) were 9 (7-10) and 5 (4-7) as presented in table 2.

We cross-tabulated median optimism and pessimism scores with gender, living status (with \& without family) and future specialty preference using Mann Whitney $U$ test. Optimism score was significantly lower among male as compared to female students $(p=0.019)$. Pessimism scores were higher among students living with their family $(p=0.008)$. Specialty preference has shown no effect on either score. $(p>0.05)$. Kruskal Wallis test was applied to determine the distribution of optimism and pessimism scores across five years of study in medical college. There was non-significant difference for optimism and pessimism scores across fiver years as shown in table 3. 
Table 1: Sociodemographic profile of the studied medical students $(n=150)$

\begin{tabular}{|c|c|c|c|}
\hline \multicolumn{3}{|c|}{ Characteristics } & $\mathrm{n}(\%)$ \\
\hline \multicolumn{3}{|c|}{ Age in Years $($ Mean $\pm \mathrm{SD})$} & $21.6 \pm 1.7$ \\
\hline \multirow{2}{*}{\multicolumn{2}{|c|}{ Sex of respondents }} & Male & $34(22.7 \%)$ \\
\hline & & Female & $116(77.3 \%)$ \\
\hline \multirow{5}{*}{$\begin{array}{l}\text { Year of } \\
\text { study }\end{array}$} & \multirow[t]{3}{*}{ Preclinical } & First year & $17(11.3 \%)$ \\
\hline & & Second year & $31(20.7)$ \\
\hline & & Third year & $27(18 \%)$ \\
\hline & \multirow{2}{*}{ Clinical } & Fourth year & $45(30 \%)$ \\
\hline & & Final year & $30(20 \%)$ \\
\hline \multirow{2}{*}{\multicolumn{2}{|c|}{ Living with family }} & Yes & $43(28.7 \%)$ \\
\hline & & No & $107(71.3 \%)$ \\
\hline \multirow{2}{*}{\multicolumn{2}{|c|}{ Specialty preference }} & People oriented & $99(66 \%)$ \\
\hline & & Technology oriented & $51(34 \%)$ \\
\hline
\end{tabular}

Table 2: Descriptive statistics of Optimism and pessimism (LOT-R) scores among of the study medical students $(\mathrm{n}=150)$

\begin{tabular}{|l|l|l|}
\hline Measure & Optimism Score ${ }^{\#}$ & Pessimism Score $^{\#}$ \\
\hline Mean & 8.16 & 5.35 \\
\hline Standard deviation & 2.41 & 1.95 \\
\hline Median & 9 & 5 \\
\hline $1^{\text {st }}$ Quartile & 7 & 4 \\
\hline $3^{\text {rd }}$ Quartile & 10 & 7 \\
\hline${ }^{\#}$ Distributionwas not normally distributed (Significant Shapirowilk test) \\
\hline
\end{tabular}


Table 3: Effect of socio-demographic factors on distribution of Optimism and Pessimism Scores $(n=150)$

\begin{tabular}{|c|c|c|c|c|c|c|}
\hline \multicolumn{2}{|c|}{ Variables } & \multirow[t]{2}{*}{ n } & \multirow{2}{*}{$\begin{array}{l}\text { Mean Rank } \\
\text { for Optimism } \\
\text { Score }\end{array}$} & \multirow[t]{2}{*}{$\mathrm{p}$ value } & \multirow{2}{*}{$\begin{array}{c}\text { Mean Rank for } \\
\text { Pessimism } \\
\text { Score }\end{array}$} & \multirow[t]{2}{*}{$\mathrm{p}$ value } \\
\hline & & & & & & \\
\hline \multirow[t]{2}{*}{ Gender $^{*}$} & Male & 34 & 60.35 & \multirow[t]{2}{*}{$.019^{r}$} & 85.24 & \multirow[t]{2}{*}{.132} \\
\hline & Female & 116 & 79.9 & & 72.65 & \\
\hline \multirow{2}{*}{$\begin{array}{l}\text { Living with } \\
\text { family }^{*}\end{array}$} & Yes & 43 & 70.5 & \multirow[t]{2}{*}{.367} & 90.23 & \multirow[t]{2}{*}{$0.008^{2}$} \\
\hline & No & 107 & 77.5 & & 69.58 & \\
\hline \multirow{2}{*}{$\begin{array}{l}\text { Specialty } \\
\text { preference }\end{array}$} & People-oriented & 99 & 71.6 & \multirow[t]{2}{*}{.122} & 74.91 & \multirow[t]{2}{*}{.816} \\
\hline & $\begin{array}{c}\text { Technology- } \\
\text { oriented }\end{array}$ & 51 & 83.05 & & 76.64 & \\
\hline \multirow{5}{*}{$\begin{array}{l}\text { Year of } \\
\text { study }^{\#}\end{array}$} & First & 17 & 94.06 & \multirow[t]{5}{*}{.206} & 66.18 & \multirow[t]{5}{*}{.71} \\
\hline & Second & 31 & 78.55 & & 73.56 & \\
\hline & Third & 27 & 77.28 & & 70.54 & \\
\hline & Fourth & 45 & 73.46 & & 80.58 & \\
\hline & Fifth & 30 & 63.3 & & 79.63 & \\
\hline \multicolumn{7}{|c|}{ * Using Mann Whitney Test } \\
\hline \multicolumn{7}{|c|}{ " Using Kruskal Wallis Test } \\
\hline \multicolumn{7}{|c|}{${ }^{\checkmark}$ Statistically significant difference } \\
\hline
\end{tabular}




\section{Discussion}

Optimism gives a meaning to life and events. Physicians with a positive attitude adapt easily to complex situations. Optimism is a powerful filter and positive personality attribute, which reform the characteristics of future physicians.7, 17, 19, 20 In the current study participants, mean $( \pm S D)$ optimism and pessimism scores were $8.16 \pm 2.4$ and $5.35 \pm 1.95$ while median scores (Q1, Q3) were $9(7,10)$ and $5(4,7)$. We found that the optimism and pessimism scores are acceptable among medical students in different years. When we compare optimism score in our population with the general population and patients, we find nonsignificant difference.1, 4, 5 In the current study, male were foundto be less optimistic as compared to female medical students $(p=0.019)$. The difference may be due to experiential learning difference among male and female. Taking reality by head needs a positive attitude, male may have become less optimistic. Other studies have proposed that female medical students are usually more empathetic because of difference in caring attitude21, 22 but we were unable to retrieve any previous study addressing the gender difference in optimism level. In a study by Hojat et al, the researchers found a positive correlation between optimism and empathy. 6 So empathy may be the underlying construct in current situation.

We tested the hypothesis that is there a difference in optimism/pessimism score regarding the choice of future specialty. Specialty preference has shown no effect on either score $(p>0.05)$. The results in our study fails to reject the null hypothesis. The current sample data suggests that choice of future specialty does not affect the optimism level. The students who intended to choose people oriented specialities like peadatrics, gynecology, internal medicine are not different than those who intend to opt radiology, intervention cardiology..

The burnout among medical students is a real epi- demic as reported in many studies and it is also associated with negative personality attribute like pessimism.6, 11, 12 We tested hypothesis that is medical training killing the optimistic soul among freshmen in medical college. The results of current study don't suggest such finding. There is niether decrease in optimism score among the students passing through five years of study nor increase in pessimism score. This can be explained by the assumption that those choosing people-oriented have more affinity to their profession and social welfare than those choosing techoriented, who may have a basic underlying goal to earn.

However, the underlying correlations between empathy and optimism have been studied at conceptual level.200ur study also gives an insight that there is significant difference in pessimism score and living status. Students who live with their families are more likely to be pessimistic compared to those living alone in hostels. These results did not correlate with a theory based on parental investment, which suggests that females tend to develop more care for the off springs 23. This also did not correlate with gender differences based on role expectations,i.e., female tend to develop more interpersonal relationships than men, have more humanistic, and care oriented attitudes.23-26The major strengths of our study are high response rate(86\%) and use of a validated instrument for optimism.

Conclusion:

We can conclude that our medical students are optimistic. The medical training does not reduce the optimism with time i.e. there is no association between optimism score and duration of study in medical college. Optimism and pessimism scores were not found associated with future specialty preference of medical students. Pessimism was affected by current living status. Female students were more optimistic as compared to their male 
counterparts.

Limitations of the study: Limitations include single center study, smaller sample size and nonprobability sampling.

Conflict of Interest: I hereby declare no conflict of interests.

Funding: This study was self-funded.

\section{References}

Bancroft, J. D., \& Gamble, M. (2008): Theory and practice of histological techniques: Elsevier Health Sciences.

Cheng, S. J., Lee, J. J., Kok, S. H., Chou, C. H., Chang, H. H., Yang, H., . . Kuo, M. Y. (2011): Expression of vascular endothelial growth factor is significantly associated with progression and prognosis of oral squamous cell carcinomas in Taiwan. J Formos Med Assoc, 110(1), 50-57. doi:10.1016/S0929-6646 (11)60008-9.

Djordjevic, J., Djordjevic, A., Adzic, M., Niciforovic, A., \& Radojcic, M. B. (2010): Chronic stress differentially affects antioxidant enzymes and modifies the acute stress response in liver of Wistar rats. Physiol Res, 59(5), 729736.

Golbar, H. M., Izawa, T., Wijesundera, K. K., Tennakoon, A. H., Katou-Ichikawa, C., Tanaka, M., . . . Yamate, J. (2014): Expression of nestin in remodelling of alphanaphthylisothiocyanate-induced acute bile duct injury in rats. J Comp Pathol, 151(2-3), 255263. doi:10.1016/j.jcpa.2014.05.003.

Jafari, M., Salehi, M., Zardooz, H., \& Rostamkhani, F. (2014): Response of liver antioxidant defense system to acute and chronic physical and psychological stresses in male rats. EXCLI J, 13, 161-171.

Johnson, K. E., \& Wilgus, T. A. (2014): Vascular Endothelial Growth Factor and Angiogenesis in the Regulation of Cutaneous Wound Repair. Adv Wound Care (New Rochelle), 3(10), 647661. doi:10.1089/wound.2013.0517.
Klein, D., Meissner, N., Kleff, V., Jastrow, H., Yamaguchi, M., Ergun, S., \& Jendrossek, V. (2014): Nestin(+) tissue-resident multipotent stem cells contribute to tumor progression by differentiating into pericytes and smooth muscle cells resulting in blood vessel remodeling. Front Oncol, 4, 169. doi:10.3389/ fonc.2014.00169.

Koenig, S., Probst, I., Becker, H., \& Krause, P. (2006): Zonal hierarchy of differentiation markers and nestin expression during oval cell mediated rat liver regeneration. Histochem Cell Biol, 126(6), 723-734. doi:10.1007/s00418006-0204-3.

Liang, Z. W., Wang, Z., Chen, H., Li, C., Zhou, T., Yang, Z., . . . Cai, W. (2015): Nestinmediated cytoskeletal remodeling in endothelial cells: novel mechanistic insight into VEGFinduced cell migration in angiogenesis. Am J Physiol Cell Physiol, 308(5), C349-358. doi:10.1152/ajpcell.00121.2014.

Liu, F., Zhang, Y., Lu, M., Wang, C., Li, Q., Gao, Y., . . . Meng, X. (2017): Nestin servers as a promising prognostic biomarker in non-small cell lung cancer. Am J Transl Res, 9(3), 13921401.

Martinez, C. E., Smith, P. C., \& Palma Alvarado, V. A. (2015): The influence of plateletderived products on angiogenesis and tissue repair: a concise update. Front Physiol, 6, 290. doi:10.3389/fphys.2015.00290.

Ramos-Vara, J. A., \& Miller, M. A. (2014): When tissue antigens and antibodies get along: revisiting the technical aspects of immunohistochemistry--the red, brown, and blue technique. Vet Pathol, 51(1), 42-87. doi:10.1177/ 0300985813505879.

Shi, A. M., Tao, Z. Q., Wang, X., \& Wang, Y. Q. (2016): Intermediate filament Nestin and the cell motility in cancer - a review. Eur Rev Med Pharmacol Sci, 20(17), 3514.

Srikumar, B. N., Raju, T. R., \& Shankaranarayana Rao, B. S. (2007): Contrasting effects of bromocriptine on learning of a partially baited 
radial arm maze task in the presence and absence of restraint stress. Psychopharmacology (Berl), 193(3), 363-374. doi:10.1007/s00213007-0801-4.

Toi, M., Hayashi, Y., \& Murakami, I. (2018):
Hepatic stellate cells derived from the nestin-positive cells in septum transversum during rat liver development. Med Mol Morphol, 51(4), 199-207. doi:10. 1007/s00795-0180183-1. 